\title{
Treatment of Otomycosis in Ears with Tympanic Membrane Perforation is Easier with Paper Patch
}

\author{
Original Investigation Kemal Görür (D), Onur İsmi (D, Cengiz Özcan (D), Yusuf Vayısoğlu (ib \\ Department of Otorhinolaryngology, Mersin University School of Medicine, Mersin, Turkey
}

\begin{abstract}
Objective: To assess the effectiveness of paper patch closure of tympanic membrane perforation in patients with otomycosis and tympanic membrane perforation.

Methods: Fifty-six otomycosis patients with central tympanic membrane perforations were included in the study. Patients were randomized into two groups as patched (PG) and non-patched (NPG) groups. In both groups, Castellani's solution was applied to the external auditory canal. In PG patients, the perforated tympanic membrane was covered with carbon paper patch soaked in Castellani's solution to reduce ear canal humidity and to prevent fungi from passing from the ear canal to the middle ear mucosa. Paper patch was not used in NPG patients.
\end{abstract}

Results: There were statistically significant differences between the two groups in terms of severity scores in the first, second, third, fourth and sixth weeks of admission ( $\mathrm{p}=0.004, \mathrm{p}=0.018, \mathrm{p}=0.001, \mathrm{p}=0.009$, and $\mathrm{p}<0.001$, respectively). Time to complete recovery was statistically shorter in $P G$ patients $(\mathrm{p}<0.001)$. Disease recurrence was statistically less among $\mathrm{PG}$ patients compared to NPG patients ( $\mathrm{p}=0.025)$.

Conclusion: Closing of perforation with paper patch and topical application of Castellani's solution was found to be an effective and safe method. The method eliminated otomycosis in a shorter period and reduced recurrence rate in patients with eardrum perforation.

Keywords: Otomycosis, fungal infection, ear surgery, tympanic membrane perforation, Castellani's solution
ORCID IDs of the authors: K.G. 0000-0002-2147-4673; 0.I. 0000-0001-5061-8907; Y.V. 0000-0002-7132-1317; C. $0.0000-0001-7409-2057$

Cite this article as: Görür K, ismi 0, Özcan C, Vayısoğlu Y. Treatment of Otomycosis in Ears with Tympanic Membrane Perforation is Easier with Paper Patch. Turk Arch Otorhinolaryngol 2019; 57(4): 182-6.

\section{Corresponding Author:}

Onur İsmi, dronurismi@gmail.com

Received Date: 22.04.2019 Accepted Date: 19.08.2019

Content of this journal is licensed under a Creative Commons Attribution 4.0 International License. Available online at www.turkarchotolaryngol.net

\section{Introduction}

Otomycosis is a superficial mycotic infection of the external auditory canal (EAC), the eardrum, and the middle ear. It can commonly occur as a primary infection or develop as a secondary infection $(1,2)$. It is more common in humid climates and in hot seasons, but rare in cold seasons. Other causes that may lead to fungal ear infection are swimming, foreign bodies in the EAC, poor hygiene, use of hearing aids, diabetes mellitus, and tympanic membrane perforation (3).

Otomycosis presents with several complaints such as itching, otalgia, mild discharge, hearing loss, and a sense of foreign body in the external auditory canal (2-5). Further, it results in inflammation, suppuration, pain, epithelial and fungal debris. Grayish white debris is commonly seen on ear examination. The most commonly responsible strains are Aspergillus niger and Candida albicans. Strains can vary according to the geographic location (4-6).

Management of otomycosis may be challenging especially in patients with tympanic membrane perforation. The initial steps in the treatment of otomycosis are aspiration of fungal debris, epithelial exfoliation and application of topical anti-mycotic solutions or powders such as boric acid with alcohol and Castellani's solution $(5,6)$. These solutions may have an ototoxic effect in patients with tympanic membrane perforation. During inspiration, ambient air moisturizes the nasal mucosa and reaches the nasopharynx (7).In patients with tympanic membrane perforation moist air travelling through the nasopharynx may reach the middle ear and possibly the EAC when the $\mathrm{Eu}-$ stachian tube opens to ventilate the middle ear. To 
the best of our knowledge, our hypothesis of traveling of moist nasopharyngeal air to the middle ear and the EAC has not been reported in the English literature so far. Also, secretions, sweating and ambient moist air in the middle ear can create a convenient environment in the EAC for fungal infection development (3). Closure of the perforation may be the important step in the medical management of otomycosis. Surgical closure of the tympanic membrane perforation must be performed after otomycosis is fully eliminated (8).

In this study, we aimed to block the connection between the middle ear and the EAC to prevent recurrence and allow for the rapid healing of otomycosis. To that end, the perforation in the tympanic membrane was covered with carbon paper patch soaked in Castellani's solution. After this temporary closing of the perforation, Castellani's solution was applied using port-cotton under otomicroscopic examination. This is the first study that reports the use of paper patch in patients with otomycosis and perforated tympanic membrane.

\section{Methods}

Approval from the local ethics committee (Nov 25, 2012-No: 2012/378) and written informed consent from all patients included in the study were obtained. Fifty-six otomycosis patients with central tympanic membrane perforation were included in the study from January 2013 to September 2018. Otomycosis was diagnosed by otomicroscopic examination with physical findings such as whitish ear discharge and/or appearance of hyphae in the EAC, the ear drum or the middle ear mucosa. Patients with intact tympanic membrane, retraction pocket, cholesteatoma, previous ear surgery, psoriasis, seborrheic dermatitis, eczema, previous use of antibiotics, topical corticosteroids or antifungal medication, patients using hearing aid in the affected ear were excluded. Diabetes mellitus and allergic rhinitis were accepted as additional risk factors (9). The 56 patients were randomized into two groups as patched (PG) and non-patched (NPG). In both groups, Castellani's solution (containing $0.08 \mathrm{~g}$ boric acid, $0.4 \mathrm{~g}$ phenol, $0.04 \mathrm{~g}$ fuchsine, $0.8 \mathrm{~g}$ resorcinol, $0.4 \mathrm{~mL}$ acetone, $0.85 \mathrm{~mL}$ alcohol, and $10 \mathrm{~mL}$ distilled water) was applied to the external auditory canal by portcotton after ear discharge and debris aspiration. Systemic or topical antifungal medication or boric acid solution were not used. In PG patients, the perforated tympanic membrane was covered with a sterilized patch of carbon paper, which is used for typing on a manual typewriter, and soaked in Castellani's solution to prevent secretion from the middle ear to the external auditory canal. The patch was not applied in NPG patients. The severity of otomycosis was scored according to the physical findings and extensiveness of the hyphae in the EAC, the tympanic membrane and the middle ear mucosa as ' 0 =none' (no mycotic infection), ' $1=$ mild' (mycotic hyphae on one side of the EAC), '2=moderate' (mycotic hyphae on two or more sides of the EAC and in the tympanic membrane), ' $3=$ severe' (diffuse mycotic hyphae involving the EAC and the middle ear) (Figure 1). Complete recovery (score $=0$ ) was defined as total dryness in the EAC and in the middle ear mucosa without any hyphae or discharge. Spontaneous closure of the tympanic membrane perforation was not seen in any patients and not regarded as an essential factor for complete recovery.

After baseline examination, and aspiration of secretion and debris in the middle ear and the EAC, patients were followed-up at first, second, third, fourth and sixth week visits (total six visits with the initial baseline visit) in the six week period. In each visit, all patients were examined under otomicroscope, Castellani's solution was applied to the external auditory canal by portcotton in each visit only once, and the current disease severity score was recorded. If the patient had complete recovery (score $=0$ ), Castellani's solution was not applied, but the patient was asked to return the following week for recurrence follow-up. The outcomes between PG and NPG patients were compared based on the following parameters: 1) number of patients by disease severity score at each visit, 2) time to complete recovery (disease severity score $=0$ ), 3) number of patients with recurrence after complete recovery during follow-up.

\section{Statistical Analysis}

Statistical analysis was performed using SPSS version 23.0 (SPSS Inc., IBM, Armonk, NY, USA). Data were shown as mean $\pm \mathrm{SD}$ for continuous variables and the number of cases was
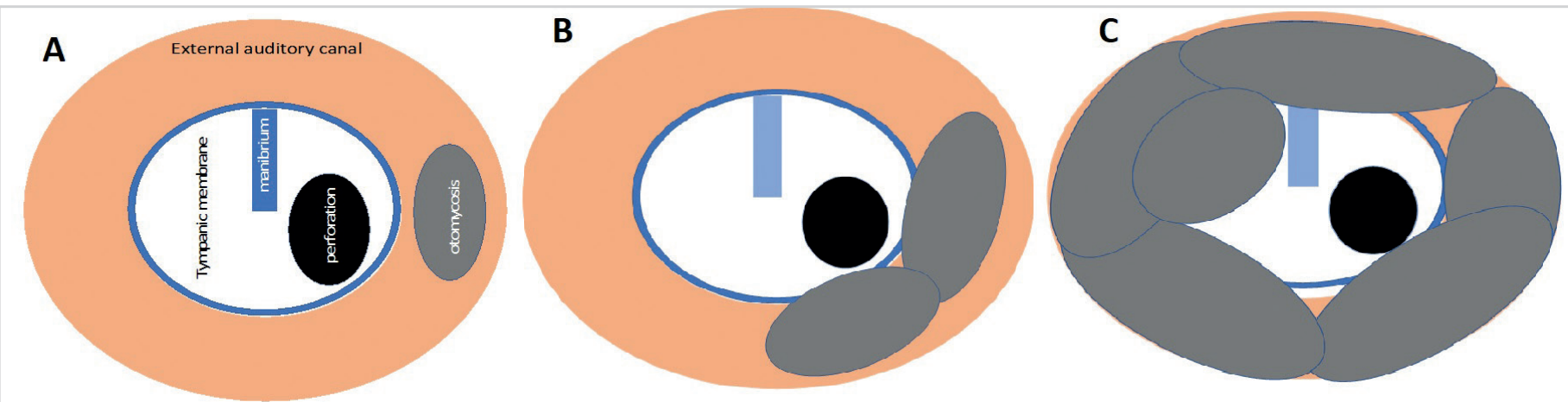

Figure 1. Severity of otomycosis was scored according to the physical findings and the extensiveness of the hyphae in the EAC, the tympanic membrane and the middle ear mucosa

1A: Mild (Mycotic hyphae on one side of the EAC)

1B: Moderate (Mycotic hyphae on two or more sides of the EAC and the tympanic membrane)

1C: Severe (Diffuse mycotic hyphae involving the EAC and the middle ear) 
used for categorical variables. Data were checked for normal distribution using the Shapiro-Wilk test. The Chi-square test was used for comparing gender differences and the Student's t-test was used for comparing age differences between PG and NPG patients. The Chi-square test was also used for comparing the categorical variants between the two groups, such as the number of cases by disease severity scores at weekly visits, the number of patients with disease recurrence in the course of the study, and the number of patients with additional risk factors. The Mann-Whitney U test was used for comparing the time to complete recovery between PG and NPG patients. P value of $<0.05$ was regarded as statistically significant.

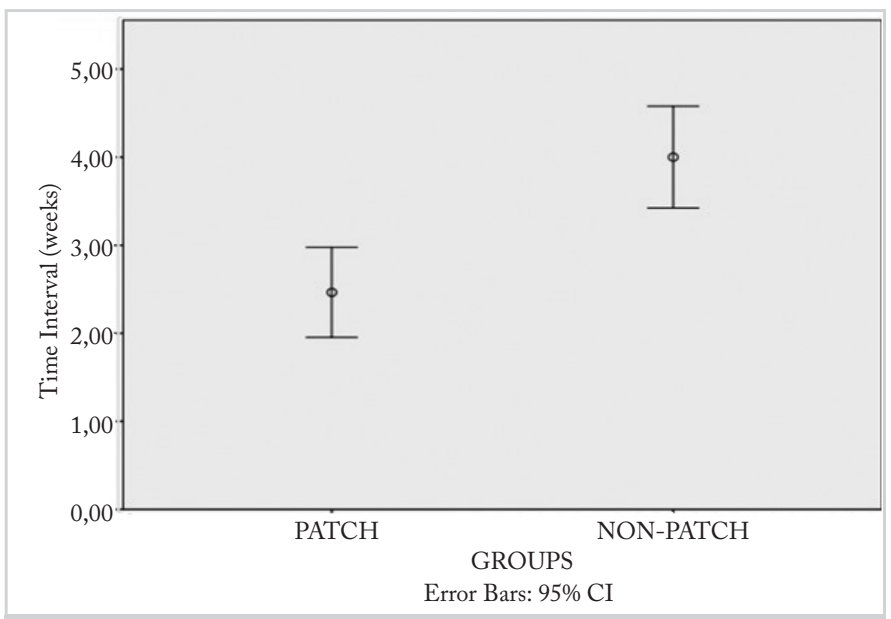

Figure 2. Comparison of the two groups in terms of time to complete recovery

\section{Results}

There were 18 males, 10 females (total 28) in PG and 15 males, 13 females (total 28) in NPG. Mean age of PG patients was $48.07 \pm 15.25$ and mean age of NPG patients was $48.25 \pm 15.56$. There were no statistically significant differences between the groups in terms of gender and age $(p=0.587$ and $p=0.966$, respectively).

Four of the PG patients had diabetes mellitus and one had allergic rhinitis, while three of the NPG patients had diabetes mellitus and one had allergic rhinitis as additional risk factor. There was no statistically significant difference between the two groups in terms of additional risk factors $(\mathrm{p}=0.716)$.

Demographic characteristics of the groups are summarized in Table 1. There was no statistically significant difference between the number of patients in the two groups regarding baseline severity scores $(\mathrm{p}=0.618)$.

There were, however, statistically significant differences between the number of patients in the two groups regarding severity scores in the first, second, third, fourth and sixth weeks of admission $(p=0.004, p=0.018, p=0.001, p=0.009$, and $p<0.001$, respectively) (Table 2). As summarized in Table 2 , the number of patients with complete recovery (score $=0$ ) was higher in $\mathrm{PG}$ at all follow-up visits.

Mean time to complete recovery was $2.46 \pm 1.31$ weeks in PG patients, and $4 \pm 1.49$ weeks in NPG patients. There was statistically significant difference between the groups regarding the time to complete recovery $(\mathrm{p}<0.001)$ (Figure 2$)$.

Table 1. Demographic characteristics of patient groups

\begin{tabular}{|c|c|c|c|}
\hline & Patched Group (PG) & Non-Patched Group (NPG) & $\mathrm{p}$ \\
\hline GENDER M/F (\%) & $18(64.3) / 10(35.7)$ & $15(53.6) / 13(46.4)$ & 0.587 \\
\hline $\mathrm{AGE}(\mathrm{Mean} \pm \mathrm{SD})$ & $48.07 \pm 15.25$ & $48.25 \pm 15.56$ & 0.966 \\
\hline \multirow[t]{2}{*}{ ADDITIONAL RISK FACTOR } & $4 \mathrm{DM}$ & $3 \mathrm{DM}$ & 0.716 \\
\hline & $1 \mathrm{AR}$ & $1 \mathrm{AR}$ & \\
\hline
\end{tabular}

M: male; F: female; DM: diabetes mellitus; AR: allergic rhinitis

Table 2. Comparison of number of patients according to disease severity scores in the time intervals and comparison of number of patients with disease recurrence between groups

\begin{tabular}{|c|c|c|c|c|c|c|c|c|c|}
\hline & \multicolumn{4}{|c|}{$\begin{array}{c}\text { Patched Group (PG) } \\
\text { Disease Severity Score (n/\%) }\end{array}$} & \multicolumn{4}{|c|}{$\begin{array}{l}\text { Non-Patched Group (NPG) } \\
\text { Disease Severity Score (n/\%) }\end{array}$} & \multirow[b]{2}{*}{$\mathrm{p}$} \\
\hline & 0 & 1 & 2 & 3 & 0 & 1 & 2 & 3 & \\
\hline Baseline & 0 & $5(17.8)$ & $13(46.5)$ & $10(35.7)$ & 0 & $8(28.6)$ & $13(46.4)$ & $7(25)$ & 0.618 \\
\hline $1^{\text {st }}$ week & $6(21.5)$ & $18(64.3)$ & $3(10.7)$ & $1(3.5)$ & $3(10.7)$ & $8(28.6)$ & $15(53.6)$ & $2(7.1)$ & $0.004^{*}$ \\
\hline $2^{\text {nd }}$ week & $15(53.6)$ & $12(42.9)$ & $1(3.5)$ & 0 & $6(21.4)$ & $16(57.1)$ & $6(21.4)$ & 0 & $0.018^{*}$ \\
\hline $3^{\text {rd }}$ week & $21(75)$ & $6(21.4)$ & $1(3.5)$ & 0 & $7(25)$ & $16(57.1)$ & $5(17.8)$ & 0 & $0.001^{*}$ \\
\hline $4^{\text {th }}$ week & $23(82.1)$ & $5(17.9)$ & 0 & 0 & $12(42.9)$ & $15(53.6)$ & $1(3.5)$ & 0 & $0.009^{*}$ \\
\hline $6^{\text {th }}$ week & $28(100)$ & 0 & 0 & 0 & $14(50)$ & $14(50)$ & & & $0.00^{*}$ \\
\hline Disease Recurrence & $1(3.5)$ & & & & $8(28.6)$ & & & & $0.025^{*}$ \\
\hline
\end{tabular}


When disease recurrence rates were compared between the two groups, disease recurrence was statistically less in PG patients than in NPG patients $(\mathrm{p}=0.025)$ (Table 2).

\section{Discussion}

In the presented study, there was statistically significant improvement in PG patients in disease recurrence rates and severity scores in the first, second, third, fourth and sixth weeks of follow-up. Further, the number of patients with complete recovery was higher in $\mathrm{PG}$ at all visits.

Otomycosis is a chronic fungal infection of the EAC with acute exacerbation. It can be frequently seen in chronic otitis media and in the canal wall-down mastoidectomy cavity. It can develop as secondary infection by several predisposing factors such as swimming, hot weather, dry and dusty working environment, loss of cerumen, immune deficiency and tympanic membrane perforation $(10,11)$. One of the most important factors for otomycosis is long-term exposure to moisture. The risk of infection is five times higher in swimmers than in non-swimmers. Longterm treatment with topical antibiotic and steroid solutions are the other predisposing factors (3).

Molds (Aspergillus), yeast (Candida species) and dermatophytes are the most commonly isolated fungi in patients with otomycosis. In our previous study, we found bilateral fungal infection in 10 of 50 patients with otomycosis, and chronic otitis media was the most common predisposing factor (12). In this previous study mycologic examination showed Aspergillus species in $56.6 \%$, Candida species in $16.7 \%$, and Penicillium species in $10 \%$. Mixed infection was found in $46.3 \%$ (12). EAC fungal infection is generally diagnosed by history, otomicroscopic and mycological examination. In our present study, all patients were diagnosed by otomicroscopic examination.

Otomycosis occurs as an acute or chronic noninvasive infection and frequently recurs in patients with tympanic membrane perforation or a tympanostomy tube (3). The infection often affects the tympanic membrane as well as the EAC. In our study otomycosis was graded according to the physical findings and the extensiveness of the hyphae in the EAC and in the tympanic membrane.

Otomycosis by itself can also cause tympanic membrane perforation (13). Persistent tympanic membrane perforation allows fungi to involve the middle ear. Otomycosis is mostly seen in adult patients with tympanic membrane perforation and otorrhea. Clinical signs of chronic fungal infection are commonly seen in the EAC. Long-term relapsing otorrhea and repeated treatment with antibiotics without remission are the characteristic features of these patients (14). Closure of the perforation with paper patch has a dual effect in the management of otomycosis. First, this technique closes the passage, reduces humidity in the EAC and prevents the secretion and the humidity coming from the middle ear. Reduced humidity in the EAC facilitates the treatment of otomycosis. Second, in patients with tympanic membrane perforation and otomycosis, perforation functions as a gateway for fungi to pass to the middle ear. Passing of the fungi to the middle ear through the perforated tympanic membrane leads to edema and inflammation in the middle ear mucosa, causing continuous discharge from the ear canal. Closure of the tympanic membrane with paper patch precludes the passage of the fungi to the middle ear and hinders middle ear mucosa inflammation as well as chronic ear discharge.

Different antifungal formulations such as ointments, sprays, solutions, gels and creams can be used in patients with otomycosis without tympanic membrane perforation. These types of medication should not be used in patients with tympanic membrane perforation. Because the small-particle content of these medications can cause inflammation and development of granulation tissue in the middle ear, topical medication will not be suitable in patients with a perforated eardrum (14). Topical antifungal solutions (ear drops) will be more suitable in this group unless the ear drop is ototoxic.

Presence of otomycosis is also a contraindication for middle ear surgeries. Therefore, tympanoplasty is not suggested in patients with otomycosis due to the risk of fungal infection spreading to the middle ear or beyond. Moreover, infection can also cause graft failure (4).

In the present study, closure with paper patch and treatment with Castellani's solution of the tympanic membrane perforations reduced the recurrence rate of fungal infections and shortened the treatment period. Castellani's solution is a well-known topical medication commonly applied to the EAC after fungal debridement or cleansing. Başal et al. (15) demonstrated that Castellani's solution did not develop any middle ear mucosa inflammation in rats when applied through a perforated tympanic membrane. It was also shown that Castellani's solution did not affect distortion product otoacoustic emission amplitudes in rats when applied to the middle ear mucosa (16). On the other hand, the ototoxic effects of topical antifungal medications are not clearly known. They can cause sensorineural hearing loss in patients with tympanic membrane perforations. Currently, antifungal otic drops contain alcohol, solvents, acids and antiseptics. These substances can pass through the round window into the cochlea and cause ototoxicity $(13,17,18)$. Five topical antimycotic drugs were administered into the middle ear of experimental animals during a 7-day period (18). Clotrimazole, miconazole, and tolnaftate have potentially safer antimycotic effect than nystatin for the treatment of otomycosis in patients with a perforated eardrum (18). Closure of the tympanic membrane with paper patch protects the inner ear from the probable ototoxic effects of topical medications.

\section{Conclusion}

Otomycosis is a serious condition in patients with tympanic membrane perforation. Closing the perforation with paper patch and topically applying Castellani's solution can be used effectively and safely. This approach completely treats the otomycosis in a shorter period and reduces the rate of recurrence in patients with eardrum perforation by reducing the humidity in the EAC and by preventing the spread of fungi to the middle ear. 
Ethics Committee Approval: Ethics committee approval was received for this study from the Clinical Research Ethics Committee of Mersin University (Nov 25, 2012-No: 2012/378).

Informed Consent: Written informed consent was obtained from the patients who participated in this study.

Peer-review: Externally peer-reviewed.

Author Contributions: Concept - K.G., O.İ., Y.V., C.Ö.; Design K.G., O.İ., Y.V., C.Ö.; Supervision - K.G., O.İ., Y.V., C.Ö.; Fundings - K.G., O.İ., Y.V., C.Ö.; Materials - K.G., O.İ., Y.V., C.Ö.; Data Collection and/or Processing - K.G., O.İ., Y.V., C.Ö.; Analysis and/ or Interpretation - K.G., O.İ., Y.V., C.Ö.; Writing - K.G., O.İ., Y.V., C.Ö.; Critical Reviews - K.G., O.İ., Y.V., C.Ö.

Conflict of Interest: The authors have no conflicts of interest to declare.

Financial Disclosure: The authors declared that this study has received no financial support.

\section{References}

1. Barati B, Okhovvat SAR, Goljanian A, Omrani MR. Otomycosis in central Iran: a clinical and mycological study. Iran Red Crescent Med J 2011; 13: 873-6.

2. Agarwal P, Devi LS. Otomycosis in a rural community attending a tertiary care hospital: assessment of risk factors and identification of fungal and bacterial agents. J Clin Diagn Res 2017; 11: 14-8. [CrossRef]

3. Gharaghani M, Seifi Z, Mahmoudabadi AZ. Otomycosis in Iran: a review. Mycopathologia 2015; 179: 415-24. [CrossRef]

4. Ho T, Vrabec JT, Yoo D, Coker NJ. Otomycosis: clinical features and treatment implications. Otolaryngol Head Neck Surg 2006; 135: 787-91. [CrossRef]

5. Pontes ZB, Silva AD, Lima Ede O, Guerra Mde H, Oliveira NM, Carvalho Mde F, et al. Otomycosis: a retrospective study. Braz J Otorhinolaryngol 2009; 75: 367-70. [CrossRef]

6. Munguia R, Daniel SJ. Ototopical antifungals and otomycosis: a review. Int J Pediatr Otorhinolaryngol 2008; 72: 453-9.
7. Randy ML, Walsh WE, Kern RC. Sinonasal anatomy and physiology. Ferguson BJ, Ryan MW editors. Bailey's Head and Neck Surgery - Otolaryngology. $5^{\text {th }}$ ed. Baltimore: Lippincott Williams \& Wilkins; 2014; Ch23, pp:359-370.

8. Badali H, Fakhim H, Zarei F, Nabili M, Vaezi A, Poorzad N, et al. In vitro activities of five antifungal drugs against opportunistic agents of Aspergillus Nigri complex. Mycopathologia 2016; 181: 235-40. [CrossRef]

9. del Palacio A, Cuétara MS, López-Suso MJ, Amor E, Garau M. Randomized prospective comparative study: short term treatment with ciclopiroxolamine (cream and solution) versus boric acid in the treatment of otomycosis. Mycoses 2002; 45: 317-28. [CrossRef]

10. Pata YS, Ozturk C, Akbas Y, Gorur K, Unal M, Ozcan C. Has cerumen a protective role in recurrent external otitis? Am J Otolaryngol 2003; 24: 209-12. [CrossRef]

11. Pata YS, Oztürk C, Akbaş Y, Unal M, Görür K, Ozcan C. Microbiology of cerumen in patients with recurrent otitis externa and cases with open mastoidectomy cavities. J Laryngol Otol 2004; 118: 260-2. [CrossRef]

12. Özcan C, Ünal M, Görür K, Öztürk C, Delialioğlu N. Otomycosis: a clinicomycological study and efficacy of alcohol boric solution in treatment. KBB Klinikleri 2000; 2: 71-5.

13. Song JE, Haberkamp TJ, Patel R, Redleaf MI. Fungal otisis externa as a cause of tympanic membrane perforation: a case series. Ear Nose Throat J 2014; 93: 332-6. [CrossRef]

14. Vennewald I, Klemm E. Otomycosis: diagnosis and treatment. Clin Dermatol 2010; 28(2): 202-11. [CrossRef]

15. Başal Y, Günel C, Eryılmaz A, Tuğrul I, Toka A, Kaçar F, et al. The effects of topical Burow's and Castellani's Solutions on the middle ear mucosa of rats. J Int Adv Otol 2015; 11: 253-6. [CrossRef]

16. Gültekin E, Yener M, Özdemir İ. The effect of topical Castellani solution on outer hair cell function of rats. Laryngoscope 2010; 120: 808-12. [CrossRef]

17. Marsh RR, Tom LWC. Ototoxicity of antimycotics. Otolaryngol Head Neck Surg 1989; 100: 134-6. [CrossRef]

18. Tom LWC. Ototoxicity of common topical antimycotic preparations. Laryngoscope 2000; 110: 509-16. [CrossRef] 